\begin{tabular}{|ccc|}
\hline & Uniqbu Journal of Social Sciences (UJSS) \\
\hline Volume 1 & Nomor 3, Desember 2020 & Halaman 176-183 \\
\hline
\end{tabular}

\title{
NILAI EDUKASI DALAM NOVEL PARTIKEL KARYA DEWI LESTARI (The Value of Education in Particle Novels by Dewi Lestari)
}

\author{
Susiati $^{\mathrm{a}}$, A. Yusdianti Tenriawali ${ }^{\mathrm{b}}$, Suraya Mukadar ${ }^{\mathrm{c}}$, Joleha Nacikit ${ }^{\mathrm{d}}$, Nursin ${ }^{\mathrm{e}}$ \\ abcdeUniversitas Iqra Buru
}

Jln. Prof. Dr. H. A. R. Bassalama, M.Si, Namlea, Indonesia

Pos-el: susiatiuniqbu@gmail.com

tenriawali@gmail.com

surayamukadar880@gmail.com

(Diterima: 26 November; Direvisi: 01 Desember; Disetujui: 08 Desember)

\begin{abstract}
The purpose of this study was to identify the educational value of the novel Partikel by Dewi Lestari. This type of research is descriptive qualitative with a dynamic structuralism approach. The method used in this research is the observation method with the note-taking technique. The data was collected by classifying and describing the elements of literary works that were the subject of the study which emphasized the values that exist in the novel Partikel. The data source is the novel Partikel by Dewi Lestari, while the research data is sentences, phrases, and words that contain an educational value. The results showed that the educational value contained in the novel Partikel by Dewi Lestari is 1) the value of religious education; 2) the value of moral education; 3) social education value is a value that teaches people to be better towards themselves, other people, animals, and nature. The educational value contained in the novel Partikel by Dewi Lestari includes attitudes and ways of life of a person such as being loyal to friends, tolerance, determination, helping and preserving animals and nature; 4) the value of cultural education.
\end{abstract}

Keywords: value, education, novel, partikel

\begin{abstract}
Abstrak
Tujuan penelitian ini adalah mengidentifikasi nilai edukasi novel Partikel karya Dewi Lestari. Jenis penelitian ini adalah deskriptif kualitatif dengan pendekatan strukturalisme dinamis. Metode yang digunakan dalam penelitian ini adalah metode simak dengan teknik catat. Pengumpulan data dilakukan dengan mengklasifikasikan dan mendeskripsikan unsur karya sastra yang menjadi pokok telaah yang menekankan pada nilai-nilai yang ada dalam novel Partikel. Sumber data adalah novel Partikel karya Dewi Lestari sedangkan data penelitian adalah kalimat, frasa, dan kata yang mengandung nilai edukasi. Hasil penelitian menujukkan bahwa nilai edukasi yang terdapat dalam novel Partikel karya Dewi Lestari adalah 1) nilai pendidikan religious; 2) nilai pendidikan moral; 3) nilai pendidkan sosial merupakan nilai yang mengajarkan manusia untuk bersikap lebih baik terhadap diri sendiri, orang lain, hewan, dan alam. Nilai pendidikan yang terdapat dalam novel Partikel karya Dewi Lestari meliputi sikap dan cara hidup seseorang seperti sikap setia kawan, toleransi, kebulatan tekad, tolong menolong dan menjaga kelestarian hewan dan alam.; 4) nilai pendidikan
\end{abstract} budaya.

Kata kunci: nilai, edukasi, novel, partikel

\section{PENDAHULUAN}

Bahasa adalah alat komunikasai yang sangat dibutuhkan dan memagang peranan penting sebagai ekspresi jiwa yang ada (Yusnan, dkk, 2020). Karya sastra diciptakan karena sastra diperlukan oleh manusia. Bagi banyak orang, misalnya karya sastra menjadi sarana untuk menyampaikan pesan tentang kebenaran, tentang apa yang baik dan buruk. Ada pesan yang kasar disampaikan, ada pula yang bersifat tersirat secara halus (Yulismayanti, dkk, 2020). Sementara Karim dkk (2020) menyatakan bahwa karya sastra merupakan wadah dari 
ide, gagasan, serta seorang pengarang mengenai gejala sosial yang ditangkap dan dialami pengarang yang dituangkan dalam bentuk karya. Susiati (2020) menyatakan bahwa sastra merupakan bagian dari manifestasi keadaan sosial kemasyarakatan. Karya sastra adalah suatu wujud yang mencerminkan perilaku, kejadian, keunikan, keberagaman masyarakat dalam setiap kurun waktu tertentu.

Segala wujud cerminan masyarakat dapat digubahdalam sebuah sketsa karya sastra dengan tidak menghilangkan nilai rasa asli dari kenyataan yang terjadi dalam masyarakat. Berdasarkan hal tersebut, jelas bahwa kesusastraan terkait erat dengan ilmu sosial yang di dalamnya mempertimbangkan aspek-aspek kemasyarakatan.

Novel berasal dari bahasa Latin novellus yang diturunkan dari kata novies yang berarti "baru", sedangkan pengertian secara etimologis novel adalah cerita yang baru muncul kemudian sesudah drama, puisi, dan lain-lain. Tarigan (dalam Zulfahnur, 1996: 66). Novel cenderung bersifat meluas dan lebih menitikberatkan kompleksitas (Sayuti, 1996: 7). Sebuah novel tidak dapat dibaca selesai dalam waktu sekali duduk. Oleh karena itu, novel dapat mengungkapkan sesuatu secara bebas, lebih rinci, dan lebih detil.

Melalui novel, pengarang dapat menampilkan nilai-nilai kehidupan yang ada dalam masyarakat. Pada hakikatnya, nilainilai kehidupan yang ada dalam novel merupakan gambaran dari rasa kemanusiaan pengarang terhadap realitas kehidupan itu sendiri. Dalam kehidupan sehari-hari, seseorang tidak dipandang sebagai individu terpisah dari yang lainnya. Ia secara langsung merupakan bagian dari masyarakat yang ada di sekitarnya (Iye, 2020)

Peneliti memilih novel Partikel karya Dewi Lestari sebagai objek yang akan diteliti dikarenakan cerita dalam novel ini banyak mengandung nilai-nilai kehidupan yang biasa kita jumpai dalam kehidupan masyarakat sehari-hari, seperti konflik antara suami dan istri, orang tua dan anak, serta menantu dan mertua. Nilai-nilai kehidupan dalam novel Partikel tergambar dengan jelas, sehingga dapat memudahkan peneliti untuk melakukan penelitian lebih lanjut.

Menurut Nurgiyantoro (2000: 4) novel merupakan suatu karya fiksi yang menawarkan suatu dunia yaitu dunia yang berisi suatu model yang diidealkan, dunia imajiner, yang dibangun melalui berbagai sistem intrinsiknya, seperti peristiwa, plot, tokoh (penokohan), latar, sudut pandang, dan nilai-nilai yang semuanya tentu saja bersifat imajiner. Dalam arti luas novel adalah cerita berbentuk prosa dalam ukuran yang luas (Jakob Sumardjo dan Saini K.M, 1988: 30). Novel cenderung bersifat meluas, novel juga memungkinkan adanya penyajian panjang lebar tentang tempat atau ruang (Sayuti, 1996: 7). Oleh karena itu, tidaklah mengherankan jika posisi manusia dalam masyarakat menjadi pokok permasalahan yang selalu menarik perhatian para novelis.

Dalam sebuah karya sastra terdapat unsur-unsur pembangunnya agar karya sastra tersebut lebih hidup dan lebih menarik. Unsur intrinsik adalah unsur-unsur yang membangun karya sastra itu sendiri. Unsur-unsur inilah yang menyebabkan karya sastra hadir sebagai karya sastra, unsurunsur yang secara faktual yang akan dijumpai jika orang membaca karya sastra, yang termasuk dalam unsur intrinsik dalam karya sastra adalah tema, alur, latar, tokoh, dan amanat. Dalam pengertiannya yang paling sederhana, tema adalah makna cerita, gagasan sentral, atau dasar cerita. Tema merupakan kaitan hubungan antara makna dengan tujuan pemaparan prosa rekaan oleh pengarangnya.

Berdasarkan beberapa pemahaman tentang novel Partikel karya Dewi Lestari maka tujuan penelitian ini, yakni mengidentifikasi nilai edukasi dalam novel Partikel karya Dewi Lestari.

\section{Nilai}

Nilai adalah sifat yang melekat pada suatu objek, bukan objek itu sendiri. 
Artinya, suatu objek akan memiliki nilai jika mempunyai kemampuan untuk menarik minat seseorang atau kelompok. Ada delapan jenis nilai, yakni

1. Nilai-nilai ekonomis (ditujukan oleh harga pasar dan meliputi semua benda yang dapat dibeli)

2. Nilai-nilai kejasmanian (yaitu kesehatan, efisiensi, dan keindahan tubuh)

3. Nilai-nilai hiburan (nilai-nilai permainan dan waktu senggang yang dapat menyumbangkan pada pengayaan kehidupan)

4. Nilai-nilai sosial (berasal dari keutuhan kepribadian dan sosial yang diinginkan)

5. Nilai-nilai watak (keseluruhan dari keutuhan kepribadian dan sosial yang diinginkan)

6. Nilai-nilai estetis (nilai-nilai keindahan dalam alam dan karya seni)

7. Nilai-nilai intelektual (nilai-nilai pengetahuan dan pengajaran tentang kebenaran)

8. Nilai-nilai keagamaan Walter G. Everet (dalam Kaelan, 2010).

Nilai memiliki sifat yang abstrak artinya tidak dapat diamati melalui indera manusia, namun dalam realisasinya nilai berkaitan dengan tingkah laku atau segala aspek kehidupan manusia yang bersifat nyata. Setiap nilai memiliki nilai dasar yang merupakan hakikat, esensi, intisari, atau makna yang terdalam dari nilai-nilai tersebut. Oleh sebab itu, nilai harus lebih berguna dalam menuntun sikap dan tingkah laku manusia agar dapat diformulasikan menjadi lebih objektif sehingga memudahkan manusia untuk menjabarkannya dalam tingkah laku secara nyata dalam kehidupan sehari-hari.

\section{Nilai Edukasi}

Pendidikan merupakan usaha manusia untuk menumbuhkan dan mengembangkan potensi-potensi pembawaan baik jasmani maupun rohani sesuai dengan nilai-nilai yang ada dalam masyarakat dan kebudayaan (Ihsan, 2011). Pendidikan bagi kehidupan manusia merupakan kebutuhan mutlak yang harus dipenuhi sepanjang hayat, tanpa pendidikan mustahil manusia dapat hidup berkembang sejalan dengan aspirasi (citacita) untuk maju dan sejahtera menurut konsep pandangan hidup mereka.

Cita-cita atau tujuan yang ingin dicapai dalam pendidikan harus dinyatakan secara jelas. Dengan demikian, pelaksanaan dan sasaran pendidikan akan lebih terarah. Bila tidak mempunyai tujuan yang jelas maka proses pendidikan akan kabur. Nilai pendidikan yang ditemukan penulis dalam novel Partikel karya Dewi Lestari ini, meliputi setia kawan, toleransi, kebulatan tekad, tolong menolong, dan kepedulian terhadap hewan dan alam.

\section{METODE PENELITIAN Jenis Penelitian}

Jenis Penelitian yang digunakan adalah deskriptif kualitatif. Jenis penelitian deskriptif kualitatif dengan menggunakan pendekatan struktural dinamis. Deskriptif kualitatif merupakan salah satu prosedur penelitian yang menghasilkan data deskriptif berupa ucapan atau tulisan dan perilaku orang-orang yang diamati (Bodgan dan Taylor dalam Susiati, 2020). Sementara itu, pendekatan strukturalisme dinamis dimaksudkan sebagai penyempurnaan strukturalisme yang semata-mata memberikan intensitas terhadap struktur intrinsik yang dengan sendirinya melupakan aspek-aspek ekstrinsiknya.

\section{Metode dan Teknik Pengumpulan Data}

Metode yang digunakan dalam penelitian ini adalah metode simak, yakni dengan membaca dan memahami suatu objek dari narasi pengarang atau tingkah laku tokoh. Sementara itu, teknik pengumpulan data menggunakan teknik simak (Susiati, 2020). Teknik catat dilakukan oleh peneliti dengan mencatat data dari keseluruhan novel Partikel karya Dewi Lestari berupa narasi pengarang atau dialog antartokoh yang menunjukkan adanya 
nilai edukasi dalam novel Partikel karya Dewi Lestari.

\section{Sumber dan Jenis Data}

Sumber data dalam penelitian ini adalah novel Partikel karya Dewi Lestari. Novel ini dicetak oleh PT Bentang Pustaka dan diterbitkan pada tahun 2012. Jenis data dalam penelitian ini adalah narasi pengarang, dialog antartokoh yang berupa frase, klausa, kalimat serta semua kejadian yang ada dalam novel Partikel yang menggambarkan nilai edukasi.

\section{Teknik Analisis}

Data Analisis data dalam penelitian ini dilakukan dengan tahapan sebagai berikut 1) Pengidentifikasian data, yakni mengidentifikasi nilai edukatif melalui kalimat narasi pengarang atau dialog-dialog para tokoh dalam novel Partikel karta Dewi Lestari; 2) Pengklasifikasian data, yakni mengklasifikasi kalimat dari narasi pengarang dan dialog antartokoh yang mencerminkan nilai edukatif dalam novel Partikel karta Dewi Lestari; 3) Penganalisisan data, yakni semua data yang telah diklasifikasi dianalisis dengan mendeskripsikan secara mendetail permasalahan yang ada dalam penelitian ini berupa nilai edukatif dalam novel Partikel karya Dewi Lestari.

\section{PEMBAHASAN}

\section{Nilai Edukasi dalam Novel Partikel Karya Dewi Lestari}

Adapun nilai-nilai edukasi yang ditemukan dalam novel Partikel karya Dewi Lestari adalah nilai pendidikan religious, nilai pendidikan moral, nilai pendidikan sosial, nilai pendidikan budaya.

\section{Nilai Pendidikan Religius}

Nilai pendidikan religi adalah suatu kesadaran yang menggejala secara mendalam dalam lubuk hati manusia sebagai human nature. Ilmu agama tidak hanya menyangkut segi kehidupan secara lahiriah melainkan juga menyangkut keseluruhan diri pribadi manusia secara total dalam integrasinya suatu hubungan ke dalam keesaan Tuhan. Nilai pendidikan religi bertujuan untuk mendidik agar manusia lebih baik menurut tuntunan agama dan selalu ingat kepada Tuhan.

Nilai pendidikan agama yang terdapat dalam novel Partikel karya Dewi Lestari adalah tokoh "Jalaluddin dan Istrinya" yang mendidik anak-anaknya supaya menjalankan syariat agama islam, mendekatkan diri kepada Allah Swt, melaksanakan shalat, menunaikan zakat, dan lain-lain. Berikut ini contoh datanya.

\section{"Semenjak}

kecil,

Hamid Jalaludin/Abah (panggilan untuk kakeknya) dan Umi (panggilan untuk neneknya) selalu menanamkan nilai-nilai keagamaan kepada anak-anaknya. Dan lagi, Abah adalah seorang kiai, agamawan yang disegani di kampung tersebut. Firas pun semasa kecilnya terlihat pandai. Karena itulah, Abah mengambilnya sebagai anak-anak kandungnya adalah Aisyah"

Nilai-nilai religius yang terkandung dalam karya seni dimaksudkan agar penikmat karya tersebut mendapatkan renungan-renungan batin dalam kehidupan yang bersumber pada nilai-nilai agama. Nilai-nilai religius dalam seni bersifat individual dan personal.

\section{Nilai Pendidikan Moral}

Moral merupakan makna yang terkandung dalam karya seni, yang disaratkan lewat cerita. Moral merupakan kemampuan seseorang membedakan antara yang baik dan yang buruk.

Pendidikan moral yang terdapat dalam novel Partikel karya Dewi Lestari adalah bersikap mawas diri, menjadi pribadi yang pemaaf, tidak sombong, selalu membantu, penyayang dan lain-lain. Berikut ini contoh datanya

"Pulang dari Kalimantan, Zarah bukannya meminta maaf kepada kakeknya, tetapi justru meminta izin kepada ibunya 
untuk mencari Firas. Ia meminta izin untuk bekerja di luar negeri untuk menjadi seorang fotogafer. di Bolivia, Zarah menemukan cinta pertamanya, Storm. Ia juga menemukan sahabat pertamanya, Koso. Namun, ternyata dua orang yang sangat berarti dalam hidupnya itu justru menikam dari belakang. Kejadian itu membuat Zarah semakin memfokuskan diri untuk melanjutkan pencarian ayahnya yang sempat tertunda"

Pendidikan moral yang terkandung dalam karya seni bertujuan untuk mendidik manusia agar mengenal nilai-nilai etika merupakan nilai baik buruk suatu perbuatan, apa yang harus dihindari, dan apa yang harus dikerjakan, sehingga tercipta suatu tatanan hubungan manusia dalam masyarakat yang dianggap baik, serasi, dan bermanfaat bagi orang itu, masyarakat, lingkungan, dan alam sekitar. Moral adalah suatu bagian dari nilai, yaitu nilai yang menangani kelakuan baik atau buruk dari manusia.moral selalu berhubungan dengan nilai, tetapi tidak semua nilai adalah nilai moral. Moral berhubungan dengan kelakuan atau tindakan manusia. Nilai moral inilah yang lebih terkait dengan tingkah laku kehidupan manusia sehari-hari.

\section{Nilai Pendidikan Sosial}

Nilai pendidikan sosial merupakan hikmah yang dapat diambil dari perilaku sosial dan tata cara hidup sosial. Perilaku sosial brupa sikap seseorang terhadap peristiwa yang terjadi di sekitarnya yang ada hubungannya dengan orang lain, cara berpikir, dan hubungan sosial bermasyarakat antar individu. Nilai pendidikan sosial yang ada dalam karya seni dapat dilihat dari cerminan kehidupan masyarakat yang diinterpretasikan. Nilai pendidikan sosial akan menjadikan manusia sadar akan pentingnya kehidupan berkelompok dalam ikatan kekeluargaan antara satu individu dengan individu lainnya.

Nilai pendidikan sosial mengacu pada hubungan individu dengan individu yang lain dalam sebuah masyarakat. Bagaimana seseorang harus bersikap, bagaimana cara mereka menyelesaikan masalah, dan menghadapi situasi tertentu juga termasuk dalam nilai sosial. Dalam masyarakat Indonesia yang sangat beraneka ragam coraknya, pengendalian diri adalah sesuatu yang sangat penting untuk menjaga keseimbangan masyarakat. Sejalan dengan tersebut nilai sosial dapat diartikan sebagai landasan bagi masyarakat untuk merumuskan apa yang benar dan penting, memiliki ciri-ciri tersendiri, dan berperan penting untuk mendorong dan mengarahkan individu agar berbuat sesuai norma yang berlaku.

Adapun nilai pendidikan sosial yang ditemukan dalam novel Partikel karya Dewi Lestari adalah

\section{a. Setia Kawan}

Setia kawan adalah perasaan yang dimiliki seseorang kepada orang lain yang dianggapnya mempunyai tujuan dan keinginan yang sama. Perasaan tersebut dapat diwujudkan dengan cara menerima kekurangan dan kelebihan masing-masing serta berjuang meraih cita-cita bersama baik dalam suka maupun duka. Hal ini dapat dilihat contoh datanya pada kutipan berikut: "Saya mau mengulang kelas 2." dan "Saya mau bantu Kosoluchukwu belajar, Bu."

Kutipan tersebut menggambarkan keadaan dimana Zarah rela berkorban demi sahabatnya Koso yang tidak naik kelas karena mempunyai kelainan otak bernama disleksia. Perbuatan yang dilakukan Zarah menunjukkan rasa kesetiakawanannya kepada Koso sehingga dia rela berkorban demi sahabatnya tersebut yang tidak naik kelas karena mempunyai kelainan otak bernama disleksia. Demi sahabatnya itu Zarah juga ingin tinggal kelas agar dapat membantu Koso dalam belajar.

\section{b. Toleransi}

Toleransi merupakan tindakan atau perbuatan yang menunjukkan sikap saling 
mengasihi, menolong, membantu, menghormati, menghargai dan lain-lain. Berikut ini merupakan sikap toleransi yang ditunjukan oleh tokoh Kim kepada tokoh Zarah yang terdapat dalam novel Partikel karya Dewi Lestari.

Sikap toleransi tersebut ditunjukkan dari sikap tokoh Kim yang tidak keberatan saat tokoh Zarah tinggal serumah dengan pacarnya, hal itu dapat dilihat contoh datanya pada kutipan

"Aku menyukai Kim. Sikapnya santai, terbuka, dan intelek. Kim nyaman-nyaman saja dengan kehadiranku sebagai penumpang di rumah Zach."

Kutipan di atas menyatakan bahwa tokoh Kim merasa tidak terganggu dengan kehadiran tokoh Zarah di rumah pacarnya. Kim mempunyai rasa toleransi terhadap keadaan Zarah yang tidak mempunyai tempat tinggal di London, sehingga Kim merasa tidak terganggu dengan keberadaan Zarah di rumah Zach. Sikap toleransi yang ditunjukkan oleh Kim kepada Zarah tersebut merupakan sikap toleransi yang biasa terjadi di negara Barat seperti London.

\section{c. Kebulatan tekad}

Tekad merupakan kemauan atau kehendak untuk berbuat sesuatu dengan sungguh-sungguh. Tekad juga bisa dikatakan sebagai kemauan yang teguh, tak tergoyahkan oleh kesulitan dan tak kendor dengan semua halangan dan rintangan. Kebulatan tekad yang ditunjukkan oleh ayah Zarah dapat dilihat contoh data pada kutipan "Ayah berusaha meyakinkan Ibu kalau sistem pendidikan swalayan dari rumah yang ia lakukan kepadaku sudah berkecukupan, bahkan jauh lebih baik ketimbang sistem sekolah biasa"

Kutipan tersebut menunjukkan bahwa ayah Zarah tetap tidak mau memasukkan Zarah ke sekolah formal meskipun keputusannya itu ditentang oleh Ibu Zarah tapi ayahnya tetap saja dengan pendiriannya. Ayah Zarah bersikokoh dengan pendiriannya bahwa pendidikan yang diterapkannya kepada Zarah lebih baik dan lebih berguna daripada sistem pendidikan yang ditawarkan oleh sekolah-sekolah yang hanya menghasilkan robot penghafal. Kebulatan tekad yang ditunjukkan ayah Zarah dalam kutipan tersebut mengambarkan kebulatan tekad seorang ayah yang ingin melindungi anaknya dan ingin memberikan yang terbaik untuk anaknya.

\section{d. Tolong Menolong}

Tolong menolong adalah suatu perbuatan yang mengarah pada bantumembantu dalam kebaikan bukan untuk kejahatan. Terdapat sikap saling menolong dalam novel Partikel karya Dewi Lestari, seperti ketika tokoh Firas yang menggunakan ilmu pengetahuan yang dimilikinya untuk membantu kemajuan Batu Luhur. Firas membantu penduduk untuk membuat penyaring air hujan yang baik dan dapat langsung di minum, seperti yang tergambar pada kutipan berikut

"Bogor, kota bercurah hujan tertinggi, dimanfaatkan ayah dengan merancang penampungan air hujan yang disambungkan ke sebuah reservoir. Di penampungan itu, air hujan difilter dengan biji kelor, kerikil, dan ijuk, hingga setiap tetes air yang dihasilkan layak minum."

Kutipan tersebut menggambarkan bagaimana cara Firas memberikan pertolongan kepada penduduk Batu Luhur dengan ilmu yang dimilikinya agar penduduk dapat memanfaatkan curah hujan yang tinggi di Bogor menjadi sesuatu yang lebih bermanfaat buat kehidupan masyarakat sekitar.

\section{e. Kecintaan Kepada Makhluk Hidup \\ Rasa cinta manusia tidak hanya} terbatas pada manusia ke manusia tetapi cinta yang patut di terapkan dalam kehidupan adalah cinta pada manusia, alam, makhluk hewan, dan tumbuh-tumbuhan. Menjaga kelestarian tumbuhan, hewan dan alam merupakan pendidikan yang harus diajarkan sejak dini kepada seorang anak, 
agar pada diri setiap anak tumbuh rasa ingin selalu menjaga kelestarian alam dan menyayangi hewan serta tumbuhan. Menjaga kelestarian alam dan hewan sangat penting, hal itu ditunjukkan contoh data pada kutipan

"Orangutan cuma bisa bertahan kalau hutan bertahan. Kalau manusia tidak bisa mempertahankan hutan, tidak cuma orangutan yang hilang.... "Manusia juga, sambungku."

Kutipan tersebut menggambarkan saat $\mathrm{Bu}$ Inga menjelaskan kepada Zarah bahwa kehidupan manusia dan orangutan tergantung pada alam. Dari kalimat tersebut dapat dilihat bahwa kehidupan seluruh mahkluk hidup dimuka bumi ini tergantung kepada alam. Jika alam ini rusak maka kehidupan juga akan hilang, seperti halnya kehidupan orangutan dan manusia. Kehidupan orangutan dan manusia sangat bergantung pada alam, manusia dapat terus hidup dan berkembang kalau alam masih menyediakan tempat untuk mereka hidup dan mau menjaga kelestarian alam. Begitu juga dengan kehidupan orangutan, kehidupan mereka tergantung dari bagaimana caranya manusia menjaga kelestarian alam, jika manusia tidak bisa menjaga alam maka kehidupan orangutan akan hilang.

\section{Nilai Pendidikan Budaya}

Nilai pendidikan budaya dianggap baik dan berharga oleh suatu kelompok masyarakat atau suku bangsa yang belum tentu dipandang baik pula oleh kelompok masyarakat atau suku bangsa lain sebab nilai budaya membatasi dan memberikan karakteristik pada suatu masyarakat dan kebudayaannya. Nilai budaya merupakan tingkat yang paling abstrak dari adat, hidup dan berakar dalam alam pikiran masyarakat, dan sukar diganti dengan nilai budaya lain dalam waktu singkat.

Nilai budaya dalam kehidupan manusia diperoleh karena manusia memaknai ruang dan waktu. Makna itu akan bersifat intersubyektif karena ditumbuh-kembangkan secara individual, namun dihayati secara bersama, diterima, dan disetujui oleh masyarakat hingga menjadi latar budaya yang terpadu bagi fenomena yang digambarkan.

Sistem nilai budaya merupakan inti kebudayaan, sebagai intinya ia akan mempengaruhi dan menata elemen-elemen yang berada pada struktur permukaan dari kehidupan manusia yang meliputi perilaku sebagai kesatuan gejala dan benda-benda sebagai kesatuan material. Sistem nilai budaya terdiri dari konsepsi-konsepsi yang hidup dalam alam pikiran sebagian besar warga masyarakat, mengenai hal-hal yang harus mereka anggap amat bernilai dalam hidup. Karena itu, suatu sisitem nilai budaya biasanya berfungsi sebagai pedoman tertinggi bagi kelakuan manusia.

\section{PENUTUP}

Berdasarkan analisis data dapat disimpulkan bahwa nilai edukasi yang terdapat dalam novel Partikel karya Dewi Lestari adalah 1) nilai pendidikan religious; 2) nilai pendidikan moral; 3) nilai pendidkan sosial merupakan nilai yang mengajarkan manusia untuk bersikap lebih baik terhadap diri sendiri, orang lain, hewan, dan alam. Nilai pendidikan yang terdapat dalam novel Partikel karya Dewi Lestari meliputi sikap dan cara hidup seseorang seperti sikap setia kawan, toleransi, kebulatan tekad, tolong menolong dan menjaga kelestarian hewan dan alam.; 4) nilai pendidikan budaya.

\section{DAFTAR PUSTAKA}

Bin-Tahir, S. Z., Suriaman, A., Hanapi, H., Iye, R., \& Umanailo, M. C. B. (2020). Development of Buru Local Language Conversation Material Based on the Communicative-Interactive Approach for Elementary School Students. Solid State Technology, 63(2s).

Bin-Tahir, S. Z. Avoiding Maluku Local Languages Death Through Embedded Multilingual Learning Model. 
Ahmadi, Abu. 2007. Sosiologi Pendidikan. Jakarta: Rineka Cipta.

Aminuddin, 2002. Pengantar Apresiasi Karya Sastra. Bandung: Sinar Baru.

Amri, M., Afifuddin, A., \& Bin-Tahir, S. Z. (2018). Religious Pluralism of the Indonesian Traditional Islamic Education Institutions. The Journal of Social Sciences Research, 4(12), 446-450.

Amri, M., Tahir, S. Z. A. B., \& Ahmad, S. (2017). The Implementation of Islamic Teaching in Multiculturalism Society: A Case Study at Pesantren Schools in Indonesia. Asian Social Science, 13(6), 125.

Endraswara, Suwardi. 2008. Metode Penelitian Sastra. Yogyakarta: Media Pressindo.

Hasbullah. 2005. Dasar-dasar Ilmu Pendidikan. Jakarta: Raja Grafindo Persada.

Iye, R., Tenriawali, A. Y., Susiati, A., \& Buton, D. (2020). Makna dan Fungsi Emosi Mahasiswa Kota Baubau dalam Ranah Demonstrasi: The Meaning And Emotional Function of Students Of Baubau City In The Demonstration Plan. Uniqbu Journal of Social Sciences, 1(1), 25-37.

Karim, Asman Budiman, Muhammad Yusnan \& Taufik. (2020). ASPEK SPIRITUAL DALAM NOVEL TUHAN IZINKAN AKU MENJADI PELACUR KARYA MUHIDIN M DAHLAN : Spiritual Aspects In The Lovely Of God Let Me Become A Property Of Muhidin M Dahlan. Uniqbu Journal of Social Sciences, $\quad 1(1), \quad 61-71$. https://doi.org/10.47323/ujss.v1i1.11

Kaelan. 2010. Pendidikan Pancasila. Yogyakarta: Paradigma.

Bin-Tahir, S. Z., Hanapi, H., Mufidah, N., Rahman, A., \& Tuharea, V. U. Revitalizing The Maluku Local Language In Multilingual Learning Model.

Bin-Tahir, S. Z., Suriaman, A., \& Rinantanti, Y. (2019). Designing English Syllabus for Multilingual Students at Pesantren Schools. Asian EFL Journal, 23(3.3), 527.

Bin-Tahir, S. Z., Atmowardoyo, H., Dollah, S., \& Rinantanti, Y. (2017). Multilingual learning program: pesantren students' perceptions of the multilingual simultaneous-sequential model. JELE (Journal Of English Language and Education), 3(2), 44-53.

Bin-Tahir, S. Z. Avoiding Maluku Local Languages Death Through Embedded Multilingual Learning Model.

Bin-Tahir, S. Z. (2020). The Role of Local Language in Intercultural Communication among Societies of Buru Island.

Bin Tahir, S. Z. (2017). Multilingual teaching and learning at Pesantren Schools in Indonesia. Asian EFL Journal, 89, 74-94.

Bin Tahir, S. Z. (2015). Multilingual Education in Pesantren Context. Yogyakarta: Deepublish.

Bin-Tahir, S. Z. (2015). The Power of Love: The Role of Boyfriend in English Language Acquisition.

Bin-Tahir, S. Z., \& Rinantanti, Y. (2016). Multilingual lecturers' competence in english teaching at the university of Iqra Buru, Indonesia. Asian EFL Journal, 5, 79-92.

Lestari, Dewi. 2012. Partikel. Yogyakarta: PT Bentang Pustaka.

Martono. 2009. Ekspresi Puitik Puisi Mawar Kalahan. Pontianak: STAIN Pontianak Press.

Moleong, Lexi J. 1991. Metode Penelitian Kualitatif. Bandung: PT Remaja Rosdakarya.

Noor, Rohimah M. 2011. Pendidikan Karakter Berbasis Sastra. Yogyakarta: Arruzz Media.

Nurgiyantoro, Burhan. 2000. Teori Pengkajian Fiksi. Yogyakarta: Gadjah Mada Universitas Press

Iye, R., \& Susiati, S. (2018). NILAI EDUKATIF DALAM NOVEL SEBAIT CINTA DI BAWAH LANGIT KAIRO KARYA MAHMUD JAUHARI ALI (Educative Values in Sebait Cinta di Bawah Langit Kairo by Mahmud Jauhari Ali). Sirok Bastra, 6(2), 185-191.

Saidah, U., Bin-Tahir, S. Z., \& Mufidah, N. (2018).

ARABIC TEACHERS'COMPETENCE: A CASE OF MADRASAH SCHOOLS IN MALUKU. Ijaz Arabi Journal of Arabic Learning, l(2). 
Salikin, H. (2018). The social media-based approach in teaching writing at Jember University, Indonesia.

Sanjaya, Wina. 2010. Kurikulum dan Pembelajaran. Jakarta: Kencana

Saripudin, Didin. 2010. Interpretasi Sosiologi dalam Pendidikan. Bandung: Karya Putra Darwati.

Sayuti, Suminto A. 1996. Apresiasi Prosa Fiksi. Jakarta.

Siswanto, Wahyudi. 2008. Pengantar Teori Sastra. Jakarta: PT Grasindo

Sumardjo, Jakob dan Saini K.M. 1988. Apresiasi Kesusastraan. Jakarta: PT Gramedia.

Suriaman, A., Bin-Tahir, S. Z., \& Usman, S. (2019). Designing Web-Based English Listening Instruction: An Analysis of Indonesian University Student's Needs. Asian EFL Journl. Vol. 23 (3.3), 28-40.

Tuasalamony, Kurniati; Hatuwe, Rahma Satya Masna; Susiati, Susiati; Masniati, Andi; Marasabessy, Roos Nilawati. (2020). PENGEMBANGAN PENDIDIKAN KARAKTER DI SEKOLAH DASAR
NEGERI 5 NAMLEA. Pedagogy. 7(2), 81-91.

Yulismayanti, Y., Harziko, H., \& Irmawati, A. (2020). KEMAMPUAN MENEMUKAN NILAI EDUKATIF DALAM CERPEN JURU MASAK KARYA DAMHURI MUHAMMAD SISWA KELAS X SMA NEGERI 12 BURU: (The Avility to Find Educative Values in Story of Master Teacher Work of Damhuri Muhammad at SMP 12 Buru). Uniqbu Journal of Social Sciences, 1(2), 35-48. https://doi.org/10.47323/ujss.v1i2.23

Yusnan, M., Kamasiah, R. I., Karim, H., \& Bugis, R. (2020). Alih Kode dan Campur Kode pada Novel Badai Matahari Andalusia Karya Hary El-parsia: Transfer Code And Mix Code In Novels Badai Matahari Andalusia Karya Hary Elparsia. Uniqbu Journal of Social Sciences, 1(1), 1-12.

Zulfahnur, dkk. 1996. Teori Sastra. Jakarta: Depdikbud. 